\title{
«HIJAS DE ISABEL» \\ DISCURSO, REPRESENTACIONES Y \\ SIMBOLIZACIONES DE LA MUJER Y DE LO \\ FEMENINO EN LA EXTREMA DERECHA ESPAÑOLA \\ DEL PERIODO DE ENTREGUERRAS
}

\author{
TERESA MARÍA ORTEGA LÓPEZ \\ Universidad de Granada
}

Recibido: 11/11/2010

Aceptado: 18/11/2010

\section{Resumen}

La experiencia política de la II República española dio lugar a la construcción, por parte de la derecha fascista, tradicionalista y ultracatólica, de una imagen fabulada de la Nación. De acuerdo con tal imagen, la Nación estaría amenazada por una heterogénea gama de agentes invasores y nocivos que asediaban su unidad y su fortaleza. En tales circunstancias, la Nación agredida precisaba, para lograr su completa regeneración, del concurso de aquellos hombres que mejor defendían los más puros valores del espíritu nacional. Pero también un nuevo modelo de mujer regenerada y patriótica jugaría un destacado papel. En los años previos a la Guerra Civil las distintas expresiones de la extrema derecha que convivieron en el seno de la II República procedieron a la redefinición y politización del modelo de feminidad que se había forjado en España a lo largo del siglo XIX. Como dignas hijas de la emblemática Isabel I de Castilla, las «verdaderas mujeres españolas» fueron llamadas a convertirse en las «capitanas» de una Cruzada. La mencionada Cruzada se dirigía, por una parte, a acabar con los enemigos de España, y por otra, a asentar las bases culturales, místicas y políticas sobre las que se llevaría a cabo la definitiva regeneración de la Nación y la raza hispanas.

Palabras clave: II República española, Guerra Civil, lenguajes políticos, fascismo, tradicionalismo, ultracatolicismo, pensamiento mítico, movilización política, mujeres, discurso de género.

Feminismo/s 16, diciembre 2010, pp. 207-232 


\begin{abstract}
The political experience of the Second Spanish Republic led to the construction, on the part of the fascist, traditionalist and ultra catholic right, of a dreamed image of the Nation. In accordance with such an image, the Nation would be threatened by a diverse range of harmful and invading agents that weakened its past unity and strength. In such circumstances, the menaced Nation needed to achieve its complete regeneration, with the help of men who best defended the purest values of the National Spirit. But also a new model of regenerated and patriotic women would play a prominent role in this main purpose. During the immediate previous years to the outbreak of the Civil War, the various kinds of the extreme right that coexisted and expanded their influence in the middle of the political experience of the Second Republic proceeded to the redefinition and politicization of the model of femininity that had been forged in Spain over the nineteenth century. As worthy daughters of emblematic Isabel of Castile, «true Spanish women» were called to become the "captains» of a true Crusade. The above-mentioned Crusade was headed, on the one hand, to put an end to the enemies of Spain, and on the other, to lay the cultural, political and mystical foundations that would make possible the final regeneration of the Spanish Nation and the Hispanic Race.
\end{abstract}

Keywords: Second Spanish Republic, Civil War, Political Languages, Fascism, Traditionalism, Ultra Catholic Right, Mythical Thought, Political Mobilization, Women, Gender Discourse. 


\section{Introducción}

A medida que avanzaba la experiencia política de la II República, las derechas españolas fueron organizando un proyecto de ordenación política instalado sobre la construcción de una imagen fabulada de la Nación. Tal proyecto se vio rodeado de un universo simbólico y un imaginario mítico hasta entonces inexistentes, aún cuando ambos deviniesen herederos de una dilatada trayectoria de pensamiento antiliberal. Un proyecto, en definitiva, erigido sobre la exaltación de una extensa panoplia de significados culturales de naturaleza fascista, tradicionalista, ultracatólica y reaccionaria, al que se adhirió un sinnúmero de representaciones y figuraciones pródigamente difundidas por una heterogénea mezcolanza de grupos sociales, que experimentaron una redefinición altamente decantada durante la guerra civil de 1936-19391. Pero antes, en su permanente búsqueda de un espacioso y multiforme agregado social de adherentes, las expresiones de naturaleza antiparlamentaria y antiliberal porfiaron, como los movimientos fascistas que irrumpieron en la escena política de la Europa de entreguerras ${ }^{2}$, en la gestación de un nutrido

1. Ver al respecto los artículos siguientes: COBO ROMERO, Francisco. «El franquismo y los imaginarios míticos del fascismo europeo de entreguerras». Ayer, 71 (2008), pp. 117151; y Cobo Romero, Francisco y OrTEga López, Teresa María. «Pensamiento mítico y energías movilizadoras: La vivencia alegórica y ritualizada de la Guerra Civil en la retaguardia rebelde andaluza, 1936-1939». Historia y política: Ideas, procesos y movimientos sociales, 16 (2006), pp. 131-158.

2. La más genuina y quintaesenciada plasmación del fascismo, encarnada en el régimen dictatorial de Mussolini, hizo posible la gestación de un nuevo fenómeno político ultranacionalista y revolucionario, propagado mediante la organización de un partidomilicia, y aureolado mediante la exaltación sacralizada de la Nación y el Estado. Los mitos y los ritos que rodearon a las dictaduras fascistas se difundieron y sedimentaron mediante la construcción de una religión política, el empleo de abundantes representaciones alegóricas del culto a la Patria, y la escenificación esteticista de una nueva ética del poder. La combinación de todas estas herramientas sería capaz de conseguir la confección idealizada de una comunidad orgánica, íntimamente cohesionada a través de poderosos lazos emotivos, y sobriamente delineada por la creatividad y el tesón de un líder excepcional y único. Véase: Berezin, Mabel, M. Making the Fascist Self. The Political Culture of Interwar Italy. Ithaca y Londres, Cornell University Press, 1997, pp. 4-7 y 2730; RoberTS, David D. «Myth, Style, Substance and the Totalitarian Dynamic in Fascist Italy». Contemporary European History, 16, 1 (2007), p. 17; GENTILE, Emilio. «Fascism,

Feminismo/s 16, diciembre 2010, pp. 207-232 
imaginario, exaltador de las virtudes espiritualizadas y eternas de la Nación Hispana ${ }^{3}$.

Desde nuestro punto de vista, pensamos que los elementos simbólicos, litúrgicos, míticos, culturales y discursivos que contribuyeron a forjar la imagen de lo que más adelante se conoció, ya en plena contienda civil, como La Nueva España por parte de las culturas políticas antidemocráticas de los años treinta deben ser entendidos como primordiales. Pues consideramos que, en buena medida, el discurso de género desplegado por tales culturas se proyectó para defender a una Nación a la que se le confirió un carácter orgánico, glorificado y épico pero que se encontraba en esos momentos gravemente amenazada por una variopinta gama de agentes invasores y nocivos que asediaban su unidad y su fortaleza, hasta colocarla en una posición de comprometida flaqueza. En tales circunstancias, la Patria agredida precisaba del concurso de hombres depositarios del mejor espíritu de la nación para lograr la regeneración de España. Hombres, pero también mujeres.

En los años treinta las tres «tradiciones» de extrema derecha que convivieron en el seno de la II República -la «teológico política» o tradicionalista, la «radical», y la «revolucionaria» o fascista- ${ }^{4}$, procedieron a la redefinición y politización del modelo de feminidad que se había forjado en España a lo largo del siglo XIX. La concesión del derecho al voto a las españolas por parte del régimen republicano en 1931 replanteó las estrategias de todos los partidos políticos y de forma especial de las derechas. Los representantes de estas formaciones políticas tuvieron que reconsiderar su antifeminismo, y aceptar definitivamente la legítima participación en política -aunque fuera accidentalmente $-^{5}$ de quienes se habían convertido en la mitad del censo electoral y, por lo tanto, en piezas claves y fundamentales para decidir el futuro gobierno de España. Apelando a las «verdaderas mujeres españolas», a las que definía como patrióticas, católicas, apostólicas y romanas, la derecha corporativa, ul-

Totalitarianism and Political Religion: Definitions and Critical Reflections on Criticism of an Interpretation». Totalitarian Movements and Political Religions, 5, 3 (2004), pp. 329-330; y Falasca-Zamponi, Simonetta. Fascist Spectacle. The Aesthetics of Power in Mussolini's Italy. Berkeley y Los Ángeles, University of California Press, 1997, pp. 9-14.

3. Este discurso de afirmación nacional se había explicitado a lo largo del siglo XX. Véase Quiroga FERnÁNDEZ DE SOTO, Alejandro. Haciendo españoles. La nacionalización de las masas en la Dictadura de Primo de Rivera (1923-1930). Madrid, CEPC, 2008. También NúÑEZ SEIXAS, Xosé Manoel. ¡Fuera el invasor! Nacionalismos y movilización bélica en la guerra civil española (1936-1939). Madrid, Marcial Pons, 2006.

4. GONZÁlez Cuevas, Pedro Carlos. «Tradiciones ideológicas de la extrema derecha española». Hispania, LXI/1, 207 (2001), pp. 99-142.

5. Pradera, Víctor. «Feminidad (II)». Ellas. Semanario de las mujeres españolas, 9 (1932), p. 1. 
tracatólica y antirrepublicana las puso al frente de una titánica y colosal empresa. Como voy a tratar de exponer en el presente artículo, las mujeres españolas eran presentadas como las hijas de Isabel I, la reina castellana y católica que había hecho posible la unidad de España y propició la condensación de los atributos raciales más esenciales, potenciando la capacidad promotora de su Imperio y dotando a la Nación Hispana de una personalidad específica, profundamente ascética, que la distinguiría del resto de las naciones europeas. Al igual que la egregia monarca, las mujeres españolas estaban llamadas a ser las «capitanas» de una Cruzada empeñada, de un lado, en acabar con los enemigos de España, y de otro, en asentar las bases culturales, místicas y políticas sobre las que se emplazaría la definitiva regeneración de la Nación y la raza hispanas ${ }^{6}$.

\section{La patria «mancillada» y «ultrajada». La construcción de un discurso ultranacionalista y anti-izquierdista en la II república}

En su permanente búsqueda de un renovado marco de conciliación entre el Estado y las masas, los fascismos persistieron en el ensayo de nuevas formas de vivencia política antidemocrática, esencialmente exaltadas y emotivas. Los totalitarismos fascistas de entreguerras hicieron posible la elaboración mitógena del permanente tránsito de la Nación desde una irremediable postergación hacia una heroica redención palingenésica, alcanzada mediante el aniquilamiento de los egoísmos sectarios y partidistas, y asentada sobre el triunfo de un revitalizador proyecto de refundación patria alumbrado en la pira expiatoria del sacrificio, la guerra y la muerte ${ }^{7}$. De esta manera, los movimientos y partidos fascistas pretendían operar una profunda redefinición en las mutuas relaciones entre las masas y el Estado, desplegando una estrategia nacionalizadora de masas impregnada de componentes ultranacionalistas, antiliberales, antiparlamentarios y antidemocráticos ${ }^{8}$.

La España del periodo de entreguerras no conoció la emergencia de un poderoso movimiento fascista. Aun cuando no cabe la menor duda acerca del elevado grado de contaminación de muchas de las propuestas teóricas y organizativas del fascismo europeo del que se vieron ungidas las más importantes

6. Pemán, José María. «Envío a las mujeres de España». Ellas. Semanario de las mujeres españolas, 1 (1932), p. 2.

7. GRIFFIN, Roger. «Il nucleo palingenetico dell'ideologia del 'fascismo generico'». En A. Campi (ed.). Che cos'é il fascismo? Roma, Ideazione Editrice, 2003, pp. 115-117, y The Nature of Fascism, Londres y Nueva York, Routledge, 1993, pp. 32-36.

8. TRAVERSO, Enzo. «Interpretar el fascismo. Notas sobre George L. Mosse, Zeev Sternhell y Emilio Gentile». Ayer, 60 (2005), pp. 234-235.

Feminismo/s 16, diciembre 2010, pp. 207-232 
formaciones políticas de la derecha española conservadora y ultracatólica9 ${ }^{9}$. El discurso ultranacionalista de los años treinta se basó en la reutilización de una vasta amalgama de elementos lingüístico-culturales, que estaban de alguna manera presentes en una tradición de nacionalismo integral, católico y reaccionario de hondas raíces históricas, éticas y políticas. En tal sentido, el mencionado discurso se sirvió del acervo del pensamiento y la tradición intelectual de raíz anti-modernista, reaccionaria, tradicionalista, autoritaria y antiliberal que se fue decantando desde las postrimerías del siglo XIX y los comienzos del XX ${ }^{10}$. Puede afirmarse, por consiguiente, que tal discurso se sintió finalmente invadido por las corrientes culturales e intelectuales del fascismo, el nacionalismo radical, el tradicionalismo católico y el antiparlamentarismo, gestadas en medio de la propagación de la política de masas acelerada tras la conclusión de la Gran Guerra. Todos estos componentes fueron aderezados, a partir de abril de 1931, con las ideas-eje de aquella versión fundamentalista y providencialista de la Historia de España que nutrirían posteriormente los idearios fascista-falangista y nacional-católico, y sobre los que se esculpiría la mayor parte del corpus ideológico del Nuevo Estado franquista ${ }^{11}$.

La trayectoria política de la II República se vio imbuida, pues, de algunas de las anomalías inducidas por la emergencia de una auténtica vorágine de propuestas extremadamente violentas y ultraderechistas, que trataban de imponer un abrupto final a las prácticas de la confrontación electoral partidista y al acatamiento de las reglas del parlamentarismo y la democracia. En consecuencia, en la España previa a julio de 1936, la derecha antirrepublicana y reaccionaria, al igual que otros regímenes de la época más o menos intensamente fascistizados, recurrió al empleo de una panoplia de instrumentos incardinados en una vigorosa corriente modeladora de los comportamientos en la arena pública, que insistió en la neutralización del avance de enemigos, internos y externos, mediante la difusión de un ultranacionalismo de raíz esencialmente antiliberal ${ }^{12}$. Además, y siguiendo en este sentido muy de

9. SAZ CAMPOS, Ismael. «Escila y Caribdis: El Franquismo, un régimen paradigmático». En J. A. Mellón (coord.). Orden, Jerarquía y Comunidad. Fascismos, dictaduras y postfascismos en la Europa contemporánea. Madrid, Tecnos, 2002, pp. 169-172; y «Fascism, fascistization and developmentalism in Franco's dictatorship». Social History, 29, 3 (2004), pp. 345-347.

10. Cerezo Galán, Pedro. El mal del siglo. El conflicto entre Ilustración y Romanticismo en la crisis finisecular del siglo XIX. Madrid, Biblioteca Nueva y Eug, 2003, pp. 633-642.

11. Сово Romero, Francisco. Op. cit., pp. 117-151; y Cobo ROMERO, Francisco y OrTEGA LÓPEZ, Teresa María. Op. cit., pp. 131-158.

12. Reig TAPIA, Alberto. La Cruzada de 1936. Mito y Memoria. Madrid, Alianza Editorial, 2006, pp. 117-121. 
cerca al fascismo, la extrema derecha española recurrió a la sacralización y la mitificación de la Patria, erigiéndola en objeto de culto. Por ello mismo, se afanó en la reconstrucción de una imagen idealizada y sublimada de la Patria Hispana y su pasado. Perseveró en la cimentación de una doctrina fuertemente nacionalizadora impregnada de definiciones organicistas, espiritualistas y trascendentes. Y, por último, reaccionó contra los agentes secularizadores y disolventes de la modernidad, incorporando una visión mística del tránsito hacia una nueva $\mathrm{era}^{13}$, instaurada sobre un imaginario sacralizado del Ser Nacional y la Nación Eterna.

Aún llena de imprecisiones y confusas explicaciones, las fuerzas contrarrevolucionarias y reaccionarias del país lograron erigir, entre 1931 y 1936, una interpretación providencialista de la Historia de España que alcanzó una redefinición altamente decantada a partir del golpe de Estado del 18 de julio. Dicha interpretación venía a identificar a los amenazadores enemigos que, desde el comienzo del siglo XIX, habían puesto fin a la unidad política de España, lograda bajo la monarquía de los Reyes Católicos, y a la limpia trayectoria ascendente del Imperio español. Tales enemigos, por su esencias materialistas y ateas, habrían provocado un profundo «descastamiento», así como una intolerable europeización de las elites políticas dirigentes, que precipitaron indefectiblemente a la Patria por la senda de una ignominia hasta ese instante desconocida. La decadencia de la Nación Hispana se deslizaría, pues, hasta una fase de intensa aceleración, auspiciada por el advenimiento del régimen democrático de la II República. En torno a este sistema político convergerían múltiples factores de crisis, así como un luctuoso cortejo de nuevos y amenazantes protagonistas que desencadenarían, supuestamente, el inicio de una etapa histórica especialmente hostil.

Según esta visión profundamente católica, tradicionalista y antiliberal, el sistema político democrático republicano habría significado la culminación, llevada hasta sus últimas e intolerables consecuencias, de un proceso de degeneración moral que había que atajar de manera ineludible. Para el discurso ultranacionalista, fascista, palingenésico, antiizquierdista y ultracatólico que

13. Las doctrinas fascistas de la Europa de entreguerras se instalaron sobre una visión recreada de los mitos del constante tránsito en la historia de las naciones hacia la búsqueda y el alcance de una idealizada era de trascendencia y elevado sentido ético, que haría posible la recuperación, por parte de cada una de ellas, y en medio de una dimensión mística y casi sagrada, de sus más puras e intemporales esencias, logrando así la superación de las lacras del individualismo, la amoralidad, la ausencia de valores y la secularización que advinieron con la irrupción de la modernidad. Véase GRIFFIN, Roger. Modernism and Fascism. The Sense of a Beginning under Mussolini and Hitler. Basingstoke, Palgrave, Macmillan, 2007, pp. 114-121 y 191-213.

Feminismo/s 16, diciembre 2010, pp. 207-232 
convivió durante la II República, las izquierdas eran reputadas como las únicas culpables de haber permitido que un monstruoso enemigo -la anti-España-, viniera cerniéndose amenazador sobre la Nación. Todas ellas eran consideradas las principales portadoras de cuantas perversidades, flaquezas y defectos repugnantes habían ocasionado la profanación de la Nación, el imparable deterioro de la salud patria, y el inadmisible envilecimiento del más íntimo sentimiento nacional ${ }^{14}$. De acuerdo con tales consignas, las izquierdas y el republicanismo democrático serían la encarnación, pues, de la anti-España. Las izquierdas obedecerían asimismo a los dictados egoístas, expansionistas o colonizadores de las potencias extranjeras. Y muy especialmente a los deseos de implantación de un régimen comunista en España, supuestamente concebidos por la Unión Soviética ${ }^{15}$. En una secuencia prolongada de descalificaciones deshumanizadoras vertidas contra las izquierdas, acusadas ahora del irreprimible deterioro de la Nación Hispana, los integrantes de la militancia izquierdista reunirían los más abominables defectos. El discurso anti-izquierdista que se fue construyendo en el transcurso del bienio reformista, 1931-1933, se instaló, de esta forma, sobre la permanente descalificación de las ideologías obreristas, republicanas e incluso liberales que habían conocido un rápido proceso de solidificación durante la corta andadura del régimen republicano. Aún cuando se manifestase con una particular inquina en contra de las doctrinas izquierdistas del marxismo (comunista o socialista) y el anarquismo. Dicho discurso propinaba a todas ellas desmesurados y abyectos calificativos que las asemejaban con poderosas e imaginarias fuerzas, que maquinaban de manera ruin y conspirativa contra el esencialismo hispanista más hondamente asentado sobre las tradiciones del catolicismo, el patriotismo, la jerarquía o la defensa de la Nación española. A todas ellas se las identificaba como portadoras de confusas propuestas organizativas, respaldadas por heteróclitos y «espurios» colectivos sociales que agrupaban a todos aquellos individuos menos instruidos o más desarraigados, y por ello mismo sustancialmente propensos a la

14. CRUZ, Rafael. «iLuzbel vuelve al mundo! Las imágenes de la Rusia Soviética y la acción colectiva en España». En R. Cruz y M. Pérez Ledesma (eds.). Cultura y movilización en la España contemporánea. Madrid, Alianza Editorial, 1997, pp. 273-303; GARCíA, Hugo. «Historia de un mito político: el peligro comunista en el discurso de las derechas españolas (1918-1936)». Historia Social, 51 (2005), pp. 3-20.

15. Fruña, Arnaldo de. «La masonería y los socialistas a favor de los Estatutos». Ellas. Semanario de las mujeres españolas, 21 (1932), pp. 10-11. Este discurso alcanzó gran difusión en plena guerra civil. Así se expone en los siguientes trabajos: SEviLlano, Francisco. Rojos. La representación del enemigo en la guerra civil. Madrid, Alianza Editorial, 2007, pp. 24-29; GONZÁLEZ CALLEJA, Eduardo. «La cultura de guerra como propuesta historiográfica: una reflexión general desde el contemporaneísmo español». Historia Social, 61, (2008), pp. 69-87, vid. especialmente las pp. 81-82. 
acción mezquina, cicatera y egoísta, o a la defensa insolidaria de sus intereses en perjuicio de la unidad patria, el prestigio nacional o el bien común.

Por mor de tales elucubraciones, de raíz fundamentalmente cultural e ideológica, se precisaba de la firme intervención de hombres y mujeres capaces de devolver a la Nación su amenazada independencia, su identidad divina, y la grandeza ancestral violentamente usurpada por la vieja casta de políticos corruptos, y sobre todo, por el egoísmo antiespañol inherente a las culturas políticas de las izquierdas «revolucionarias». Por mi parte, me detendré en el llamamiento que las derechas en su conjunto hicieron a las mujeres españolas. Un llamamiento que implicó la confección de nuevas representaciones de lo femenino, así como la gestación de un discurso politizado plagado de integrantes simbólicos, circunscrito a un poderoso imaginario de exaltación de la Nación Eterna.

\section{Mujeres y II República. Redefinición y politización del modelo de feminidad por las cultura antiliberales españolas}

Los avances experimentados a inicios del siglo XX por el movimiento feminista democrático y el sufragismo se fundieron con las manifestaciones de ansiedad, angustia vital e incertidumbre derivadas del derrumbe de los modelos jurídico-políticos, éticos y culturales sobre los que se había fundado, en la centuria anterior, la hegemonía burguesa. Entre las amenazas padecidas e interiorizadas por las elites burguesas y las clases medias conservadoras, se encontraba el ascenso de un movimiento feminista que reclamaba la igualdad jurídica de los sexos y la concesión de plenos derechos democráticos a las mujeres. La reacción a esta oleada de feminismo consistió, en buena medida, en la elaboración de múltiples discursos cargados de componentes acentuadamente misóginos, que ponían énfasis en el urgente regreso al modelo tradicional y patriarcal de la familia burguesa, en la irremisible sumisión de la mujer al hombre y en la negación de toda capacidad jurídica al sexo femenino. Desde la sociología positivista, el darwinismo social, el vitalismo, el organicismo o las teorías biológicas sobre la desigualdad de los sexos, se fue trabando un espeso magma de concepciones antifeministas, que posteriormente nutrió los postulados misóginos y androcéntricos del fascismo, el catolicismo conservador, el tradicionalismo, la extrema derecha antiliberal o el nacionalismo reaccionario ${ }^{16}$. Pero como voy a exponer a continuación, este

16. ORTEGA LÓPEZ, Teresa María. «Conservadurismo, catolicismo y antifeminismo: la mujer en los discursos del autoritarismo y el fascismo (1914-1936)». Ayer, 71 (2008), pp. 53-83.

Feminismo/s 16, diciembre 2010, pp. 207-232 
poso de formulaciones antifeministas común a la derecha reaccionaria española del periodo de entreguerras no fue obstáculo para que esa misma derecha estimase oportuna la movilización política de la mujer en aras de la auténtica consecución de una sociedad jerarquizada, desigualitaria, y profundamente ultra-católica y ultra-nacionalista.

Al proclamarse la República, las fuerzas políticas conformadoras de la derecha autoritaria y reaccionaria tenían una concepción de la mujer que en términos generales partía del siguiente principio básico procedente de la tradición católica: la desigualdad de los sexos y la subordinación de la mujer al marido dentro del matrimonio. Dos tipos de argumentos definían esta concepción. De un lado, la concepción jerárquica de la sociedad y de la familia. La derecha española, al hablar de la familia como basamento de la sociedad, se refería siempre al padre. Él representaba la autoridad, el poder y la fuerza. Al padre le correspondía la potestad de mandar y oprimir, mientras que la madre y los hijos tenían la necesidad de obedecer y ser oprimidos. En cuanto al segundo argumento, las formaciones políticas antiliberales, conservadoras y ultramontanas que vieron la luz en los años veinte y treinta en España construyeron un discurso que combinaba argumentos heredados del tradicionalismo decimonónico y otros procedentes de las modernas teorías científicas surgidas a principios del siglo pasado. Unos y otros argumentos contraponían a hombres y mujeres como dos seres diferentes, sin que aparentemente ninguno fuera superior al otro. Según este discurso, los dos géneros participaban de cualidades y esferas distintas, una objetiva y otra subjetiva, acordes con sus respectivas naturalezas. Esta concepción dimorfista de los sexos se nutría también de la filosofía organicista de la sociedad y de su fundamentación religiosa. Las derechas españolas eran partidarias de la máxima Secundum Natura, según la cual las cualidades femeninas eran producto de la diferente creación divina de ambos sexos. Hombres y mujeres tenían por tal motivo unas funciones específicas, complementarias y, en consecuencia, desiguales. Introducir cualquier cambio que distorsionara aquellas funciones o la jerarquía de los sexos era considerado como algo antinatural e inmoral.

Ahora bien, sabedores del nuevo momento histórico que había supuesto, de un lado, la proclamación de la II República en abril de 1931, y de otro, el reconocimiento por parte de este régimen político del derecho al voto a las españolas ${ }^{17}$, todos los miembros integrantes de la familia teológico-política

17. A través del artículo 36 de la Constitución de 1931, las mujeres conseguía la plena igualdad política con los hombres. Se consagraba por primera vez en el país el sufragio universal. Artículo 36.- Los ciudadanos de uno y de otro sexo, mayores de veintitrés años, tendrán los mismos derechos electorales conforme determinen las leyes. 
pronto reconocieron la importancia que podía llegar a tener la actividad política de las mujeres. De modo que no sólo readaptaron su secular discurso de domesticidad, sino que les proporcionaron a las españolas una nueva «identidad cívica» colectiva $^{18}$ sobre la que construyeron un nuevo modelo de mujer definido por dos coordenadas. La primera, su «ultracatolicismo», y la segunda, su «patriotismo». Ambas coordenadas eran sinónimo de un antirrepublicanismo extremo. La nueva coyuntura política dio lugar, pues, a un nuevo discurso patriarcal de lo femenino. Un discurso que contenía novedosas representaciones y simbolizaciones sobre las mujeres españolas. Dicho discurso, aunque siguió envuelto en un lenguaje de género tradicional, se revistió, no obstante, con nuevos elementos procedentes del mito de las «dos Españas» y del «peligro comunista», dos conceptos muy arraigados entre los políticos autoritarios ${ }^{19}$, así como de la particular visión, victimista y catastrofista, que para tales políticos tuvo el trascendental cambio de régimen político acontecido en 1931. Con este rico poso ideológico, forjado en las lecturas y relecturas de la obra de los historiadores tradicionalistas del siglo XIX, y de los intelectuales europeos de la derecha antirrevolucionaria y fascista de comienzos del siglo $\mathrm{XX}^{20}$, las derechas reaccionarias españolas procedieron a idealizar la imagen y ensanchar los roles de las mujeres católicas españolas. Éstas fueron presentadas como las «verdaderas mujeres de España». Los representantes de las culturas políticas antiparlamentarias las erigieron en símbolo de lo auténtico, de lo espiritual, de la traditio, valores esenciales de la «España eterna $»^{21}$.

Pero lo más interesante fue que cuantos se identificaron con los lenguajes políticos autoritarios y ultraconservadores enaltecieron las virtudes consideradas «propias» de la naturaleza femenina (obediencia, discreción, delicadeza,

18. Las culturas políticas republicanas también utilizaron la prensa como un vehículo apropiado para forjar entre las mujeres una identidad colectiva femenina, en este caso, republicana y secularizada. Véase en este sentido RAmOS, $\mathrm{M}^{a}$. Dolores. «Las primeras modernas. Secularización, activismo político y feminismo en la prensa republicana: Los Gladiadores (1906-1919)». Historia Social, 67 (2010), p. 102.

19. García FernándeZ, Hugo. Op. cit., pp. 3-20; y Quiroga FERnÁndeZ de Soto, Alejandro. «La idea de España en los ideólogos de la dictadura de Primo de Rivera. El discurso católico-fascista de José Pemartín». Revista de Estudios Políticos, 108 (2000), p. 211.

20. Morodo, Raúl. Acción Española. Orígenes ideológicos del franquismo. Madrid, Tucar, 1980, pp. 28-35 y 165-166; ÁlvAREZ JUNCO, José. «El nacionalismo español como mito movilizador. Cuatro Guerras». En R. Cruz y M. Pérez Ledesma. Op. cit., pp. 35-67; GonzÁlez Cuevas, Pedro Carlos. Acción Española. Teología política y nacionalismo autoritario en España (1913-1936). Madrid, Tecnos, 1998, pp. 98-101 y del mismo autor «Charles Maurras y España». Hispania, 188 (1994), pp. 993-1040.

21. Pemán, José María. «Las mujeres y las costumbres». Ellas. Semanario de las mujeres españolas, 2 (1932), p. 1.

Feminismo/s 16, diciembre 2010, pp. 207-232 
decencia, orden y devoción), por considerar que tales virtudes eran armas poderosas que estaban esperando ser utilizadas para combatir a los enemigos (externos e internos) de la Nación española. Paralelamente mostraron a sus portadoras, las mujeres «católicas y patrióticas», provistas de otras virtudes, valores y connotaciones asociados hasta ese momento al sexo masculino. La «nueva mujer católica» pasó a ser de esta forma valiente, heroica, decidida, incansable... pero siempre diferente de la degenerada y libertina «mujer moderna» europea y norteamericana.

Los políticos de las derechas radicales y fascistizadas españolas daban a entender así que las mujeres, «católicas, patrióticas y antirrepublicanas» tenían una obligación pública importante, la regeneración de la Patria hispana ${ }^{22}$ y la defensa de unos valores que se encontraban vilmente amenazados por un inesperado régimen democrático y por sus principales acólitos (republicanos, socialistas, comunistas, anarquistas, masones y separatistas). En consecuencia, aceptaron «sacar» a las mujeres españolas del hogar y procedieron a «politizar» sus comportamientos individuales y colectivos así como cuantas acciones desarrollaron aquéllas en el espacio público y privado. Todo ello para hacer frente a lo que había sido concebido como un monstruoso enemigo, la anti-España, que había osado posarse de la mano de la II República sobre la egregia, espiritual y católica Nación hispana.

Desde las filas ultraconservadoras y tradicionalistas pronto se reclamó, pues, la incorporación de las mujeres al activismo político ${ }^{23}$. La Nación las necesitaba. Así lo daba a entender uno de sus más destacados representantes, el antiguo colaborador de la dictadura de Miguel Primo de Rivera, José María Pemán y Pemartín. El prolífico escritor gaditano venía a decir: «en este momento de enfermedad de España, hace falta a su cabecera la mujer» ${ }^{24}$. Para él, las mujeres, por las virtudes señaladas, eran las que mejor podían ejecutar aquella titánica labor de regeneración ética, anímica y mística de una España

22. El carácter regenerador de la mujer había sido expuesto por algunos políticos una década antes. Véase GoicoecheA, Antonio. El feminismo político y el influjo social de la mujer. Conferencia pronunciada en la Sala Mozart de Barcelona el día 16 de diciembre de 1922.

23. Desde la CEDA se quería conseguir la movilización de las masas para lograr la transformación política. PIERCE, Samuel. «The Political Mobilization of Catholic Women in Spain's Second Republic: The CEDA, 1931-6». Journal of Contemporary History, Vol. 45, I (2010), pp. 74-94. También, Monge y Bernal, José. Acción Popular (Estudios de biología política). Madrid, Imprenta Sáez Hermanos, 1936, pp. 200-204.

24. Pemán, José María. «Envío a las mujeres de España». Ellas. Semanario de las mujeres españolas, 1 (1932), p. 1. 
ultrajada y mancillada por unos seres ruines, viles, materialistas, ateos, depravados, inmorales, incultos, analfabetos, egoístas y cobardes.

\section{4. «Todo por dios y por la paz y bien de España» ${ }^{25}$. Las mujeres investidas del arcángel San Uriel}

Nada más producirse el reconocimiento por parte de la II República del principio de igualdad jurídica entre hombres y mujeres, un sector de la derecha española comprendió que había llegado el momento de superar aquel largo y complejo debate de si las mujeres servían más para la casa que para el mun$\mathrm{do}^{26}$. Ya no era hora de pensar si la salida de la mujer del hogar «bastardearía su feminidad ${ }^{27}$. Ya no era hora de preguntarse tampoco si era aconsejable o no que las mujeres acudieran a la política. El tiempo de la discusión ya había pasado. Bueno o malo, conveniente o inconveniente, error o acierto, la realidad era que, como le gustaba decir al propio Pemán, «el voto había conquistado a la mujer $»^{28}$, y eso bastaba.

Aunque a la altura de los años treinta la intervención de las mujeres católicas en la vida social era ya una realidad constatable ${ }^{29}$, se hacía preciso, no obstante, educarlas, prepararlas y organizarlas para un terreno (el político) y una actividad (la lucha política) que les era totalmente desconocido. Las derechas españolas se apresuraron en este sentido a adoctrinar y a formar a

25. Cañizares, María de los Dolores F. «Mujeres de Hoy. María de las Nieves Saénz de Heredia y Osio». Ellas. Semanario de las mujeres españolas, 15 (1932), p. 5.

26. El debate en SCANLON, Geraldine M. La polémica feminista en la España contemporánea (1868-1974). Madrid, Akal, 1986.

27. LIS, Blanca. «Mujeres de Hoy. Doña Juana Salas de Jiménez». Ellas. Semanario de las mujeres españolas, 6 (1932), p. 2.

28. PARA José María Pemán era excesivo llamar al voto femenino una conquista de la mujer, «la palabra conquista presupone lucha y esfuerzo, y la mujer española ni se ha esforzado ni ha luchado por el voto... No ha sido una conquista de la mujer, sino un regalo del Estado». Cf. Pemán, José María. «Voto e ideas». Ellas. Semanario de las mujeres españolas, 1 (1932), p. 6.

29. Véanse los trabajos de Blasco Herranz, Inmaculada. Paradojas de la ortodoxia. Políticas de masas y militancia católica en España (1919-1939). Zaragoza, Prensas Universitarias de Zaragoza, 2003 y ARCE PINEDO, Rebeca. Dios, patria y hogar. La construcción social de la mujer española por el catolicismo y las derechas en el primer tercio del siglo $X X$. Santander, Ediciones de la Universidad de Cantabria, 2007. Sobre la movilización femenina católica véase también Villalaín, Pablo. Mujer y política. La participación de la mujer en las elecciones generales celebradas en Madrid durante la II República (1931-1936). Madrid, Instituto de la Mujer, 2000 y MORENO SECO, Mónica. «Mujeres, clericalismo y asociacionismo». En Julio de la Cueva Merino y Ángel Luis López Villaverde (coords.). Clericalismo y asociacionismo católico en España, de la Restauración a la Transición: un siglo entre el palio y el consiliario. Cuenca, Ediciones de la Universidad de Castilla-La Mancha, 2005, pp. 119-124.

Feminismo/s 16, diciembre 2010, pp. 207-232 
la población femenina de cara a futuros comicios. Hasta las elecciones generales de noviembre de 1933, la prensa nacional fue inundada con artículos, editoriales y reportajes que apuntaba en esa dirección. El simple llamamiento a las urnas no era suficiente. Había llegado el momento de «despertar a la ciudadanía femenina $»^{30} y$ atraerla a ese «baile sin ganas $»^{31}$ que era el sufragio y la democracia. Es decir, era la hora que las mujeres españolas descendieran al combate diario en la calle. Movilizarlas a favor del discurso nacionalista español frente a la amenaza revolucionaria marxista, para que ellas aseguraran la victoria de Roma sobre Moscú y salvaguardaran unos intereses y unos valores tradicionales que parecían estar al borde del abismo ${ }^{32}$. Para ello era preciso efectuar entre ellas una labor pedagógica y formativa que garantizara el triunfo electoral y el gobierno posterior. El aprendizaje político y la adquisición de disciplina y coordinación se tornaban de esta forma en enseñanzas esenciales y prioritarias. Periódicos como Ellas. Semanario de las mujeres españolas, dirigido por José María Pemán, tenían esa orientación pedagógicaformativa-movilizadora señalada. Esta publicación, en la que se dieron cita los principales representantes de Acción Popular, la Confederación Española de Derechas Autónomas (CEDA), Renovación Española, Comunión Tradicionalista y Falange Española, así como destacadas mujeres de Acción Católica y el Tradicionalismo carlista, se convirtió, sin tapujos de ninguna clase, en el azote, al igual que otros diarios católicos y monárquicos de la época, principalmente $A B C$ y El Debate $e^{33}$, o la revista Aspiraciones ${ }^{34}$, del régimen republicano y de la nueva clase dirigente. Pero a diferencia de ellos, en el semanario del monárquico gaditano, las mujeres se convirtieron en el brazo ejecutor que

30. GutiÉRREZ BALBÁs, Leopoldo. «Ciudadanía femenina en la hora presente». Ellas. Semanario de las mujeres españolas, 11 (1932), p. 2.

31. Pemán, José María. «Voto e ideas». Op. cit., p. 6.

32. PRADA, Julio. «Mujeres contra la revolución. La movilización femenina conservadora durante la Segunda República española y la Guerra Civil». Anmis. Revue de Civilisation Contemporaine de l'Université de Bretagne Occidentale, 8 (2008), http://www.univ-brest. fr/amnis.

33. SinOva, Justino. La prensa en la Segunda República española. Madrid, Debate, 2006, pp. 52-84.

34. Esta revista estaba dirigida por Carmen de Lara y su madre, Carmen Velacoracho. Se trataba de un semanario caracterizado por «la capacidad destructora de las directoras» y por «la agresividad de sus discursos y de su actuación contra el comunismo, los judíos, el separatismo y los gobiernos sucesivos de la República». No en vano, Aspiraciones nació bajo el lema «Defenderemos, hasta morir si es preciso, la Religión y la Patria». Véase Bussy GenevoIS, Danièle. «La función de directora en los periódicos femeninos (1862-1936) o la 'sublime misión'». En J. M. Desvois (coord.). Prensa, impresos, lectura en el mundo hispánico contemporáneo: homenaje a Jean-François Botrel. Université Michel de Montaigne Bordeaux 3, Press Universitaires de Bordeaux, 2005, p. 201. 
debía aniquilar para siempre a la II República. Las mujeres españolas debían encarnar el «Fuego de Dios», es decir, al Arcángel San Uriel, para expulsar del Paraíso (identificado con España) a los traidores que urdían la «invasión extranjera» y el aniquilamiento de la independencia nacional: «Con polvo y viento ha sido vencida la vieja España; por mano de mujer ha sido atado el gigante. ¿Por qué no desatarle también por mano de mujer? $\aleph^{35}$

De esta forma, las culturas políticas tradicionalistas, autoritarias y antiliberales arengaron pronta y enardecidamente a las mujeres para que participaran en aquella colosal empresa nacionalista y regeneradora ${ }^{36}$. Haciéndolas ver que su «reacción espiritualista y religiosa» estaba legitimada por la teórica «grandeza» de la tarea encomendada, y concebida como el instrumento regenerador -y palingenésico- que propiciaría no solamente la recuperación de la perdida fortaleza espiritual y política de la Patria sino, asimismo, el aniquilamiento de sus más odiados enemigos ${ }^{37}$. Ellas presentó tal empresa como la suprema reacción de las mujeres católicas y patrióticas para salvar aquellos elementos de mayor pureza espiritual (y civilizatoria) que venían siendo considerados como los ejes vertebrales de la Nación española ${ }^{38}$. El movimiento antirrepublicano se presentaba así pues como el empeño histórico colectivo, de hombres, pero muy especialmente de las «verdaderas mujeres españolas», por devolver a la Patria su menoscabado esencialismo católico y tradicionalista. Atribuyendo a la victoria sobre los enemigos un carácter regenerador, palingenésico y milenarista, íntimamente asociado a la visión exaltadora, purificadora y sublimada de la violencia de que hacía gala el fascismo de entreguerras.

La tarea anunciada por las derechas a las féminas españolas quedaba simbolizada, pues, como el crisol desde donde emergería una Nueva España, refundada y resucitada gracias a la fusión de las energías provenientes de sus más nobles y ancestrales ideales. Ante tamaña coacción a los designios de la Patria, y frente a tan desmedido asalto a los principios espirituales sustentadores de la Nación, el movimiento liberador y la rotunda respuesta frente a los enemigos se convertían en una noble e inexcusable acción. Una acción que debería ser sostenida por las auténticas mujeres españolas, visiblemente

35. Pemán, José María. «La profecía de Fray Basilio». Ellas. Semanario de las mujeres españolas, 21 (1932), p. 1.

36. GeStOSO DE MedinA, Eugenia. «Charlas». Ellas. Semanario de las mujeres españolas, 13 (1932), p. 8.

37. Pemán, José María. «Momentos espiritualistas». Ellas. Semanario de las mujeres españolas, 16 (1932), pp. 2-3.

38. RuANO, José María. «La Inmaculada y la tradición española». Ellas. Semanario de las mujeres españolas, 29 (1932), p. 6.

Feminismo/s 16, diciembre 2010, pp. 207-232 
identificadas por compartir un común sentimiento antiizquierdista, antidemocrático y de penetrante catolicismo y regeneración nacional.

\section{Heroinas nacionales de ayer, y de hoy... Representaciones y simbolizaciones de las «verdaderas mujeres españolas»}

Además de lo ya indicado, conviene también señalar que las ideas contenidas en aquel discurso movilizador, con el que se pretendía vigorizar adecuadamente la participación de las mujeres en política, asumieron en este caso una nueva forma de edificante transmisión mediante la rememoración permanente de la vida y obra de «mujeres españolas de ayer». La revista de Pemán incorporó en esa sección una amplia galería de personajes emblemáticos femeninos que habían hecho "grande» la Historia de España. Mujeres que con sus heroicas y loables acciones, con su abnegado comportamiento y, sobre todo, con su profunda fe católica habían forjado un «tipo femenino español» propio, inmortal y, en consecuencia, indestructible ${ }^{39}$. Un tipo muy superior y opuesto al de la «mujer moderna» que tanta difusión comenzaba a tener en las grandes ciudades ${ }^{40}$.

La derecha antiliberal exaltó vivamente en las páginas de Ellas ese «tipo femenino español» representado por mujeres providenciales, insignes y sacrificadas a Dios. «Grandes y gloriosas mujeres», «auténticas heroínas», «mujeres santas», pertenecientes a una «raza» que siempre se consagró a los ideales fecundos que la sublimaron: la Patria y la Religión. Tal fue el caso de Santa Teresa de Jesús, de Isabel la Católica, de Juana I de Castilla, de la princesa doña Juana (hija de Carlos V), de Rosalía de Castro, de la emperatriz Eugenia de Montijo, de Cecilia Bölh de Faber, de la Emperatriz Isabel (esposa de Carlos V), o de María «la Católica» de Inglaterra (segunda esposa de Felipe II). Pero aquella derecha también incluyó en su «galería de heroínas nacionales» otras figuras menos conocidas pero igualmente provistas de una voluntad fuerte y decidida al servicio de la Patria y de la Iglesia católica. Este fue el caso de la duquesa de Villahermosa, María Coronel, la Madre Angelita, Carmen de Sojo, la marquesa de Campoverde, Dorotea de Chopitea, Luisa de Borja, María Enríquez de Guzmán, la Beata Madre Micaela del Santísimo Sacramento, la condesa de Luna, Sancha Carrillo Fernández de Córdoba, sor

39. Ellas. Semanario de las mujeres españolas, 20 (1932), p. 4.

40. Sobre la imagen transmitida de la «mujer moderna» podemos consultar los trabajos de ARESTI, Nerea. Médicos, donjuanes y mujeres modernas. Los ideales de feminidad y masculinidad en el primer tercio del siglo XX. Universidad del País Vasco, Bilbao, 2001 y «La mujer moderna, el tercer sexo y la bohemia en los años veinte». Dossiers Feministes, 10 (2007), p. 176. 
Juana Isabel de la Cruz, Catalina Clara Ramírez de Guzmán, María Pacheco, María Jesús Coronel («la venerable de Agreda»), Carolina Coronado, María Mendoza y Antonia García. Todas ellas fueron enaltecidas por sus múltiples virtudes y bondades excepcionales para con los humildes, por su feminismo cristiano y materno, por su espiritualidad, por su sabiduría cultivada, por su humildad en la grandeza, por su templanza en el poder, por su modestia y austeridad, y por su determinación frente a la adversidad y a los enemigos de la religión católica.

Tan nobles personajes fueron ensalzados de forma mística y atemporal. Poniendo de manifiesto que aquellas excelsas virtudes y connotaciones características de las féminas históricas reseñadas constituían, como indicaba Clara Frías en su biografía de Cecilia Bölh de Faber, las señas de identidad de la «verdadera dama española $»^{41}$. De esta forma, tradicionalistas y ultraconservadores evidenciaban la existencia de un vínculo de unión entre las «auténticas mujeres españolas» de ayer y las del momento presente. No en vano, Ellas creó otra sección en su interior titulada «mujeres de hoy», en la que se constataba esa transmisión hereditaria de las virtudes enteramente hispanas. Pilar Careaga, Pilar Velasco, Teresa Luzzatti, Blanca de los Ríos, Rosa Urraca Pastor, la vizcondensa de San Enrique, Juana Salas, Mercedes Quintanilla, la marquesa de Valdeiglesias, María de la Paz Valero, Ángela García Loygorri, Leonor de Figueroa, la marquesa de Mac-Mahón, María de las Nieves Sáenz de Heredia y Osio, Lola D. Palatín, Rosa Ruiz y Martín de Vidales, la marquesa de Laula, Julia Mélida, Inés González Torreblanca, Julia Parody, María del Pilar Rodríguez, María de Piniés y Roca de Togores, la marquesa de Quintanar, mujeres todas ellas representantes de las más importantes asociaciones católicas femeninas del momento, fueron elevadas a la categoría de «heroínas nacionales», y definidas y delimitadas en consecuencia con los mismos atributos egregios, distinguidos e ilustres de las figuras femeninas españolas que destacaron en el Medievo, en el Renacimiento, en la Modernidad y en el siglo XIX.

Es decir, esas «mujeres de hoy» se distinguían, al igual que sus memorables predecesoras, por poseer una inteligencia preclara, por ser receptoras de las más nobles virtudes cristianas, por ser abnegadas hijas, esposas y madres, por ser las preceptoras de las sanas costumbres y tradiciones españolas, por estar entregadas a un sinfín de notables obras benéficas y sociales destinadas a los segmentos de la población más necesitados y precarios, y por defender con vehemencia y heroicidad, como «Agustina de Aragón en las revoluciones

41. Ellas. Semanario de las mujeres españolas, 22 (1932), p. 2.

Feminismo/s 16, diciembre 2010, pp. 207-232 
santas hechas por la independencia nacional» ${ }^{42}$, la nación española y su concepción teocrática.

Mientras las mujeres españolas siguieron la senda esplendorosa que aquellas señoras iluminaron con sus virtudes, podía la Patria, en plena decadencia, sentir un hábito inmortal que la sostuvo para honra y prez del nombre español ${ }^{43}$.

Esas virtudes eran al mismo tiempo sus principales armas para la batalla. Como hijas de Isabel la Católica, pondrían en pie a una «nación caída en un letargo mental de que sale nada más para organizar revueltas y guerras civiles ${ }^{44}$. Y como la reina castellana, combatirían tenaz e incansablemente, al lado de los hombres, como «avanzada o guardia de honor de un pasado glorioso» a los enemigos de España ${ }^{45}$. Es decir, a una República y a unos anti-españoles que, con pujos de pseudociencia y con las añagazas del lema de «libertad, igualdad y fraternidad», habían envenenado el entendimiento del pueblo y, con una corona de histrión en su frente y una tea de destrucción en sus manos, lo habían lanzado a destruir los hogares y la familia cristiana, a arruinar el porvenir de sus hijos, y a acabar con la prosperidad y la grandeza de la Patria. Pero aquellas virtudes también serían empuñadas por las herederas de Isabel para luchar contra otro enemigo no menos letal. Aquel vasto conjunto de componentes esencialistas, trascendentales, milenaristas o puramente místicos que vertebraban ese discurso movilizador e identificativo, empleado desde Ellas por las derechas de cara a la justificación de la participación política de las mujeres, también sería utilizado para acabar, de un lado, con la frivolidad, el sensualismo, la corrupción y las costumbres paganas impuestas por la modernidad, y de otro lado, con el mensaje mesiánico del feminismo igualitario y de izquierdas que había dado lugar a la mujer vulgar o «anti-mujer».

\section{La dama roja... Representaciones y simbolizaciones de las «anti- mujeres»}

La revista de Pemán presentó de manera insistente a la modernidad como un horrendo fenómeno de extravagancia, de degradación moral, y de pérdida

42. LuZZATTI, Teresa. «El deber de las mujeres en la hora presente exige unión y decisión». Ellas. Semanario de las mujeres españolas, 5 (1932), p. 1. Véase también el artículo de GutiÉRREZ BALBÁs, Leopoldo. Op. cit., p. 2.

43. El MarquÉS Del SAltillo. «Doña María Enríquez de Guzmán». Ellas. Semanario de las mujeres españolas, 13 (1932), p. 4.

44. Ellas. Semanario de las mujeres españolas, 27 (1932), p. 11.

45. Aramburu, Luisa María de. «Mujeres de Hoy. La vizcondesa de San Enrique». Ellas. Semanario de las mujeres españolas, 5 (1932), p. 2. 
absoluta de los valores más acendradamente cultivados por el espíritu del catolicismo y el nacionalismo españolista ${ }^{46}$. Aunque sus efectos perniciosos habían afectado por igual a hombres y mujeres, el escritor gaditano y el resto de sus colaboradores y colaboradoras se centraron muy especialmente en las consecuencias que aquella «enfermedad contagiosa» tuvo entre las segundas. Desde las derechas y los grupos católicos el arquetipo de la mujer moderna se convirtió en elemento constitutivo de su enemigo común. Al lado de los anti-españoles -es decir, los republicanos, los socialistas, los comunistas, los anarquistas y los nacionalistas no españolistas-, los tradicionalistas, reaccionarios y falangistas situaron a las anti-españolas, a las que concibieron como las anti-mujeres. La anti-mujer era la versión en negativo de la «auténtica mujer española». En lugar de virtudes, estaba plagada de terribles y despreciables defectos. Simbolizaba la vulgaridad, la desviación sexual y la degeneración, la trasgresión de las normas de los roles sexuales, la virago, la herejía y la revolución, la violencia, la pertenencia a un grupo politizado y subversivo ${ }^{47}$. Su debilidad de espíritu había propiciado en ella la relajación extrema del monopolio del poder de la moral católica y truncado su verdadero feminismo. Su ignorancia la había convertido en una mujer crédula e ingenua, incapaz de distinguir entre el Bien y el Mal ${ }^{48}$. Frente a la humanidad y altruismo que acompañaba a aquellas mujeres españolas de ayer y de hoy, la anti-mujer era un ser frío, calculador e impúdico ${ }^{49}$. En claro paralelismo con la imagen transmitida por el libro del Génesis, la anti-mujer era la nueva Eva que se había dejado seducir y tentar por las falaces promesas de la ladina Serpiente, identificada ahora con la modernidad, el feminismo igualitario y la República.

En la prensa de derechas encontramos múltiples cuentos, reportajes y editoriales en los que se exponían el «justo castigo» que les esperaba a aquellas mujeres que se dejaban vencer por la tentación. Al igual que la Eva expulsada del Jardín del Edén, todas las anti-mujeres estaban condenadas al sufrimiento, al dolor, a la vergüenza y a la muerte. Para la corriente de pensamiento y los lenguajes políticos identificados con el movimiento antirrepublicano, tanto las nuevas costumbres y modas impuestas por la modernidad como aquel falaz mensaje liberalizador del sexo femenino difundido por el feminismo laico

46. RuANo, José María. Op. cit., p. 6.

47. Esta imagen se reafirmó y potenció en la Guerra Civil y en la dictadura franquista. Véase al respecto: Joly, Maud. «Las violencias sexuadas de la guerra civil española: paradigma para una lectura cultural del conflicto». Historia Social, 61 (2008), p. 95.

48. Cernuda, María Teresa G. «Deberes de la mujer». Ellas. Semanario de las mujeres españolas, 16 (1932), p. 3

49. PÉREZ DE LA OSSA, Huberto. «Emancipada, pero...». Ellas. Semanario de las mujeres españolas, 26 (1932), p. 9.

Feminismo/s 16, diciembre 2010, pp. 207-232 
y por las culturas políticas de izquierda significaron para muchas mujeres una penosa profundización en el acelerado proceso de degradación moral y ruina personal en el que, hipotéticamente, habían ingresado engañadas desde, al menos, la proclamación del régimen democrático de la II República ${ }^{50}$. En consonancia con esto último, para la derecha antiliberal el régimen republicano permitió la entronización, en el seno de los hogares y de las escuelas, de toda una amalgama de valores pervertidos y comportamientos antipatrióticos. Tales valores y comportamientos se hallaban teñidos por la ruindad, la avaricia y el materialismo destilados por un régimen excepcionalmente caótico e inmoral. Por otro lado, esa misma derecha consideraba que aquel supuesto mensaje mesiánico había condenado irremisiblemente a las mujeres a una abominable y caricaturesca imitación de las formas masculinas. Léase si no el cuento de Teodoro Muñoz Crego titulado «A buscar casa». En él nos muestra a una sirvienta, Valentina, con "pelo a lo manolo», zapatos escotados y chal, que se ha educado en el «Ateneo Feminil y Libertario» leyendo a los «rusos» y que expone a su Señora cuáles son sus honorarios y derechos:

— ¿Pretensiones? Justa retribución a mis servicios, pues es un principio económico que el salario es una consecuencia o secuela del trabajo, como en el orden fisiológico, el hijo del padre. Al fin no se trata más que del cambio de dos capitales: capital industria por capital trabajo. O de otro modo: metal acuñado a trueque de sudor humano...

(...) Mis derechos, pues son éstos: en metálico quinientas pesetas mensuales, cotización Londres, sin contar propinas y otros sustitutivos más o menos inconfesables, o enchufismo vergonzante para rendir pleitesía a la actualidad... Levantarme, en invierno, de once a una, sin precisar la hora. Dos para la toaleta, tres para el trabajo... Salida todos los domingos y días festivos, cívicos y religiosos, aparte los permisos tradicionales de Nochebuena, Semana Santa, fiesta del pueblo, de la capital, de la provincia y del partido judicial ¿Qué más? ¡Ah, sí! Prohibición absoluta de regañinas, porque, en caso de reincidencia, se aplicaría a la casa, según el artículo $5^{\circ}$, párrafo $2^{\circ}$, apartado 12 del Reglamento de las 'Esclavas de la Burguesía', el 'boicot' en su forma más radical. Y más inapelable. Igualmente estarán vedadas las intromisiones en la vida íntima, cualquiera que sea el pretexto....

-Un momento, Valentina: ¿qué opina su novio de esa manera tan... novísima, por decirlo así, de pensar? ¿Supongo que tendrá usted novio?

-Con mis hijos tengo de sobra, señorita.

- ¿Luego usted es casada?

— ¿Olvida usted, señorita, que están prohibidas las intromisiones en la vida íntima? Por esta vez no he oído nada. Ya ve la señorita si soy bondadosa. Bien... Pero éstos son mis derechos ¿Quiere la señorita enumerarme mis obligaciones?

50. LuZZATTI, Teresa. Op. cit., p. 1. 
— ¿Sus obligaciones? La primera y la última, en mi casa, márchese por esa puerta ${ }^{51}$.

Como digo, son muchos los ejemplos que encontramos al respecto en las publicaciones inspiradas por las culturas políticas antiliberales. La diputada socialista Margarita Nelken fue objeto, en este sentido, de todo tipo de críticas y burlas. Llamada despectivamente «la ulano Nelken», las derechas efectuaron, en la mayoría de los casos, una definición pueril, histriónica, desfigurada y satírica de su actuación fuera y dentro del Congreso de los Diputados. Veamos un ejemplo:

A Margarita Nelken la ofenden las mujeres patriotas, sobre todo si estas mujeres son españolas o francesas. 'Ante un conflicto bélico, la sola postura decorosa es la del desertor'. Esta es la moral de la diputada socialista alemana, excelente para aplicada en España o en Francia. 'No concibo el tipo de heroína. Es más: me repugna'. Nos parece adecuado a su temperamento y a sus ideas. La miel no se ha hecho para todos los labios. 'Agustina de Aragón es un viraco (en español, Margarita, se dice virago) más que una mujer auténtica... Me parece una energúmena'. Apreciación germánica pura... 'El espectáculo que ofrecía la mujer francesa en los primeros meses de la contienda europea animando con un ardimiento feroz a los hijos de Francia para que marchasen a las trincheras, me parece la negación más rotunda de la feminidad y un acto en absoluta abominable...' Y esta mujer es diputada en el Parlamento español $^{52}$.

En una secuencia prolongada de descalificaciones vertidas contra el discurso de la igualdad, acusado ahora del irreprimible deterioro de la Nación hispana, las integrantes del movimiento feminista inspirado en la ideología izquierdista convocarían los más detestables defectos. Estableciéndose, así, que las mujeres que hiciesen causa común con «la repugnante Dama Roja» ${ }^{53}$ se convertirían indefectiblemente en seres provistos de sentimientos malignos y rastreros. En definitiva, asumirían la identidad de las anti-mujeres y de los antiespañoles. Seres, unas y otros, que debían ser exterminados, como advertía la líder y dirigente carlista María Rosa Urraca Pastor en un artículo de opinión, como paso previo para la regeneración nacional:

Vivimos en una época y unos días que se caracterizan por un signo de interrogación. Es la ansiedad del tiempo, la inquietante espera del mañana, la duda y la incertidumbre de un porvenir que se dibuja en el espacio, preñado de

51. Muñoz CRego, Teodoro. «A buscar casa». Ellas. Semanario de las mujeres españolas, 9 (1932), p. 15.

52. «Declaraciones de la ulano». Ellas. Semanario de las mujeres españolas, 30 (1932), p. 14. Véase también los comentarios contenidos en la columna: «El Parlamento». Ellas. Semanario de las mujeres españolas, 29 (1932), p. 13.

53. LuZZATTI, Teresa. Op. cit., p. 1.

Feminismo/s 16, diciembre 2010, pp. 207-232 
nubarrones negros, sobre un fondo de cielo enrojecido con los resplandores de una hoguera social puesta al rojo...

... Dios nos salvará, no lo dudéis, y sirva esto de confortador optimismo para la lucha, pero nos salvará mediante nuestro propio esfuerzo. Hay que tener confianza, seguridad en el triunfo... ¿Cuándo? A Dios no se puede señalársele fechas; pero tanto más se acelerarán éstas cuanto mayor sea nuestro sacrificio colectivo.

España ha caído en el crisol de la purificación. A gran temperatura se está fundiendo el alma del pueblo español.

A la superficie van saliendo las pasiones, los egoísmos, las venganzas, la soberbia, la vanidad... es la escoria que no sirve. Pero en el fondo quedará el acero purísimo del temple de nuestra raza, que, liquidado, irá a los moldes de la tradición para formar los lingotes que servirán para forjar los eslabones que faltan y unir de nuevo la cadena de nuestra rota Historia.

¡Benditas aquellas almas que sean capaces de resistir, hasta el fin, en el fondo del crisol!... Ad augusta per angusta ${ }^{54}$.

\section{Referencias bibliográficas}

Álvarez JunCO, José. «El nacionalismo español como mito movilizador. Cuatro Guerras». En R. Cruz y M. Pérez Ledesma. Cultura y movilización en la España contemporánea. Madrid, Alianza Editorial, 1997, pp. 35-67.

ARCE PINEDO, Rebeca. Dios, patria y hogar. La construcción social de la mujer española por el catolicismo y las derechas en el primer tercio del siglo XX. Santander, Ediciones de la Universidad de Cantabria, 2007.

ARESTI, Nerea. Médicos, donjuanes y mujeres modernas. Los ideales de feminidad y masculinidad en el primer tercio del siglo XX. Universidad del País Vasco, Bilbao, 2001.

- «La mujer moderna, el tercer sexo y la bohemia en los años veinte». Dossiers Feministes, 10 (2007), pp. 173-185.

Blasco Herranz, Inmaculada. Paradojas de la ortodoxia. Políticas de masas y militancia católica en España (1919-1939). Zaragoza, Prensas Universitarias de Zaragoza, 2003.

Berezin, Mabel M. Making the Fascist Self. The Political Culture of Interwar Italy. Ithaca y Londres, Cornell University Press, 1997.

Bussy GENEVOIS, Danièle. «La función de directora en los periódicos femeninos (1862-1936) o la 'sublime misión'». En J. M. Desvois (coord.). Prensa, impresos, lectura en el mundo hispánico contemporáneo: homenaje a Jean-François Botrel. Université Michel de Montaigne Bordeaux 3, Press Universitaires de Bordeaux, 2005, pp. 193-208.

54. UrRaca Pastor, María Rosa. «La necesidad del sacrificio». Ellas. Semanario de las mujeres españolas, 23 (1932), p. 7. 
Cerezo Galán, Pedro. El mal del siglo. El conflicto entre Ilustración y Romanticismo en la crisis finisecular del siglo XIX. Madrid, Biblioteca Nueva y Eug, 2003.

Cово Romero, Francisco. «El franquismo y los imaginarios míticos del fascismo europeo de entreguerras». Ayer, 71 (2008), pp. 117-151.

Cobo Romero, Francisco y OrTEgA López, Teresa María. «Pensamiento mítico y energías movilizadoras: La vivencia alegórica y ritualizada de la Guerra Civil en la retaguardia rebelde andaluza, 1936-1939». Historia y política: Ideas, procesos y movimientos sociales, 16 (2006), pp. 131-158.

CRUZ, Rafael. «iLuzbel vuelve al mundo! Las imágenes de la Rusia Soviética y la acción colectiva en España». En R. Cruz y M. Pérez Ledesma (eds.). Cultura y movilización en la España contemporánea. Madrid, Alianza Editorial, 1997, pp. 273-303.

FAlasCA-ZAMPONI, Simonetta. Fascist Spectacle. The Aesthetics of Power in Mussolini`s Italy. Berkeley y Los Ángeles, University of California Press, 1997.

GARCíA, Hugo. «Historia de un mito político: el peligro comunista en el discurso de las derechas españolas (1918-1936)». Historia Social, 51 (2005), pp. 3-20.

GENTILE, Emilio. «Fascism, Totalitarianism and Political Religion: Definitions and Critical Reflections on Criticism of an Interpretation». Totalitarian Movements and Political Religions, 5: 3 (2004), pp. 326-375.

GonzÁlez CAlleja, Eduardo. «La cultura de guerra como propuesta historiográfica: una reflexión general desde el contemporaneísmo español». Historia Social, 61 (2008), pp. 69-87.

GonzÁlez Cuevas, Pedro Carlos. Acción Española. Teología política y nacionalismo autoritario en España (1913-1936). Madrid, Tecnos, 1998.

— «Charles Maurras y España». Hispania, 188 (1994), pp. 993-1040.

GRIFFIN, Roger. The Nature of Fascism, Londres y Nueva York, Routledge, 1993.

- «Il nucleo palingenetico dell'ideologia del 'fascismo generico'». En A. Campi (ed.). Che cos'é il fascismo? Roma, Ideazione Editrice, 2003, pp. 97-122.

- Modernism and Fascism. The Sense of a Beginning under Mussolini and Hitler. Basingstoke, Palgrave, Macmillan, 2007.

JOLY, Maud. «Las violencias sexuadas de la guerra civil española: paradigma para una lectura cultural del conflicto». Historia Social, 61 (2008), pp. 89-107.

Monge y Bernal, José. Acción Popular (Estudios de biología política). Madrid, Imprenta Sáez Hermanos, 1936.

Moreno SECO, Mónica. «Mujeres, clericalismo y asociacionismo». En Julio de la Cueva Merino y Ángel Luis López Villaverde (coords.). Clericalismo y asociacionismo católico en España, de la Restauración a la Transición: un siglo entre el palio y el consiliario. Cuenca, Ediciones de la Universidad de Castilla-La Mancha, 2005, pp. 107-132.

Morodo, Raúl. Acción Española. Orígenes ideológicos del franquismo. Madrid, Tucar, 1980.

Feminismo/s 16, diciembre 2010, pp. 207-232 
NÚÑEZ SEIXAS, Xosé Manoel. ¡Fuera el invasor! Nacionalismos y movilización bélica en la guerra civil española (1936-1939). Madrid, Marcial Pons, 2006.

ORTEgA LóPEZ, Teresa María. «Conservadurismo, catolicismo y antifeminismo: la mujer en los discursos del autoritarismo y el fascismo (1914-1936)». Ayer, 71 (2008), pp. 53-83.

PIERCE, Samuel. «The Political Mobilization of Catholic Women in Spain's Second Republic: The CEDA, 1931-6». Journal of Contemporary History, Vol. 45, I (2010), pp. 74-94.

PRADA, Julio. «Mujeres contra la revolución. La movilización femenina conservadora durante la Segunda República española y la Guerra Civil». Anmis. Revue de Civilisation Contemporaine de l'Université de Bretagne Occidentale, 8 (2008), http://www.univ-brest.fr/amnis.

Quiroga FernÁndez DE Soto, Alejandro. «La idea de España en los ideólogos de la dictadura de Primo de Rivera. El discurso católico-fascista de José Pemartín». Revista de Estudios Políticos, 108 (2000), pp. 197-224.

- Haciendo españoles. La nacionalización de las masas en la Dictadura de Primo de Rivera (1923-1930). Madrid, CEPC, 2008.

RAMOS, M ${ }^{a}$. Dolores. «Las primeras modernas. Secularización, activismo político y feminismo en la prensa republicana: Los Gladiadores (1906-1919)». Historia Social, 67 (2010), pp. 93-112.

Reig TAPIA, Alberto. La Cruzada de 1936. Mito y Memoria. Madrid, Alianza Editorial, 2006.

RoberTS, David D. «Myth, Style, Substance and the Totalitarian Dynamic in Fascist Italy». Contemporary European History, 16, 1 (2007), pp. 1-36.

SAZ CAMPOS, Ismael. «Escila y Caribdis: El Franquismo, un régimen paradigmático». En J. A. Mellón (coord.). Orden, Jerarquía y Comunidad. Fascismos, dictaduras y postfascismos en la Europa contemporánea. Madrid, Tecnos, 2002, pp. 159-196.

— «Fascism, fascistization and developmentalism in Franco's dictatorship». Social History, 29, 3 (2004), pp. 342-357.

SCANLON, Geraldine M. La polémica feminista en la España contemporánea (18681974). Madrid, Akal, 1986.

SeVILlano, Francisco. Rojos. La representación del enemigo en la guerra civil. Madrid, Alianza Editorial, 2007.

SinOVA, Justino. La prensa en la Segunda República española. Madrid, Debate, 2006.

TRAVERSO, Enzo. «Interpretar el fascismo. Notas sobre George L. Mosse, Zeev Sternhell y Emilio Gentile». Ayer, 60 (2005), pp. 227-258.

Villalaín, Pablo. Mujer y política. La participación de la mujer en las elecciones generales celebradas en Madrid durante la II República (1931-1936). Madrid, Instituto de la Mujer, 2000. 


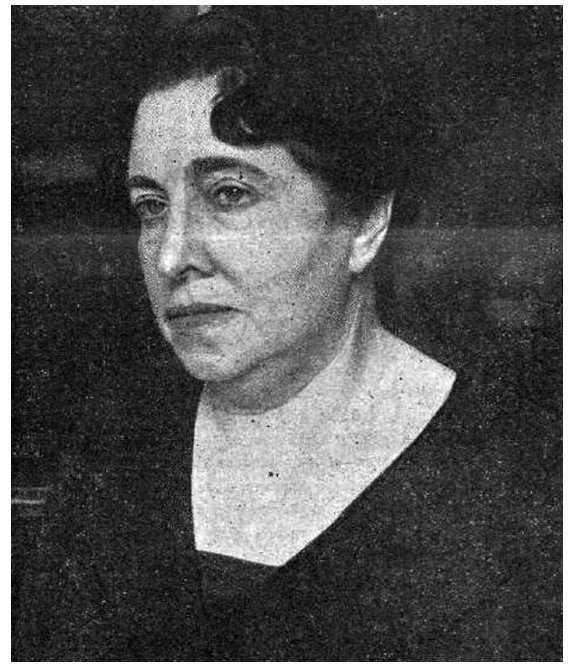

Doña María de la Concepción Kirpatrick, Marquesa de Valdeiglesias.

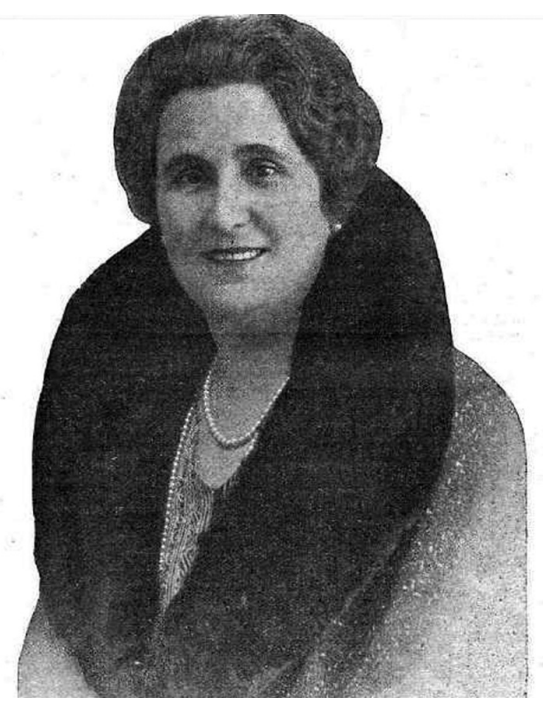

Teresa Luzzatti.

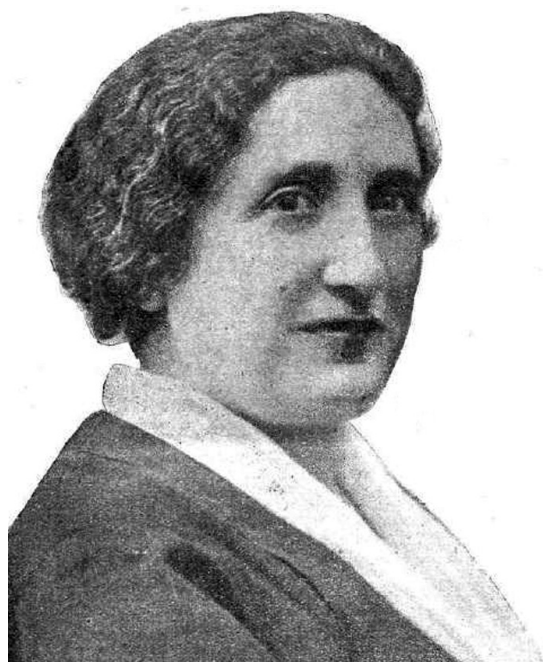

Mercedes Quintanilla.

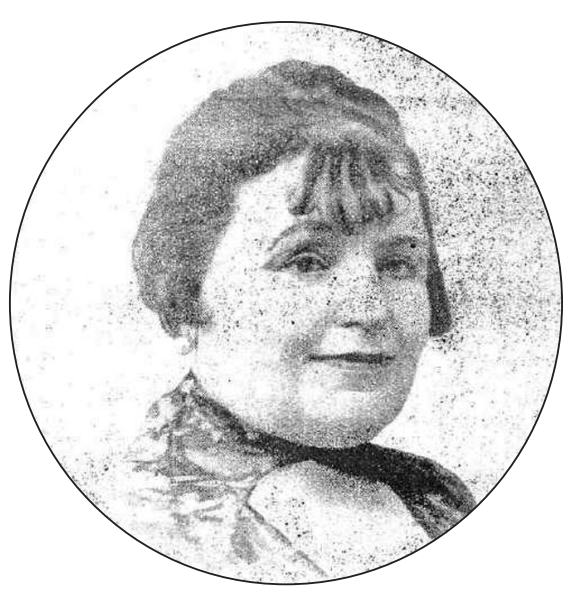

Vizcondesa de San Enrique.

Feminismo/s 16, diciembre 2010, pp. 207-232 


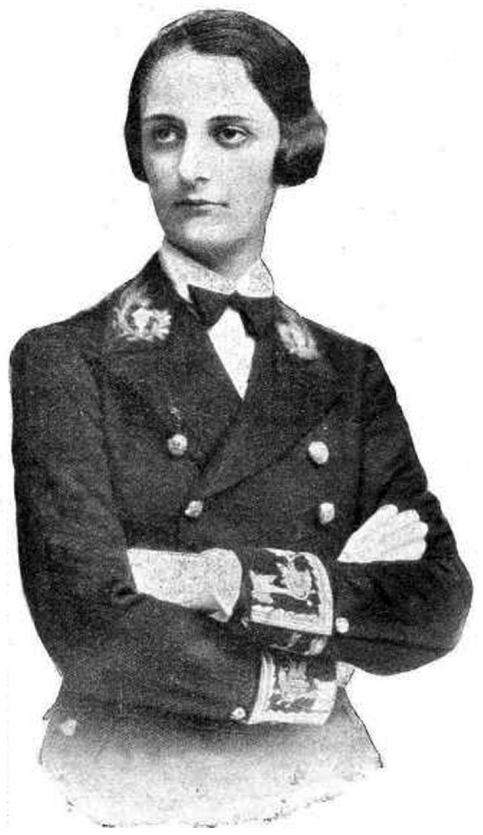

Pilar Careaga Basabe.

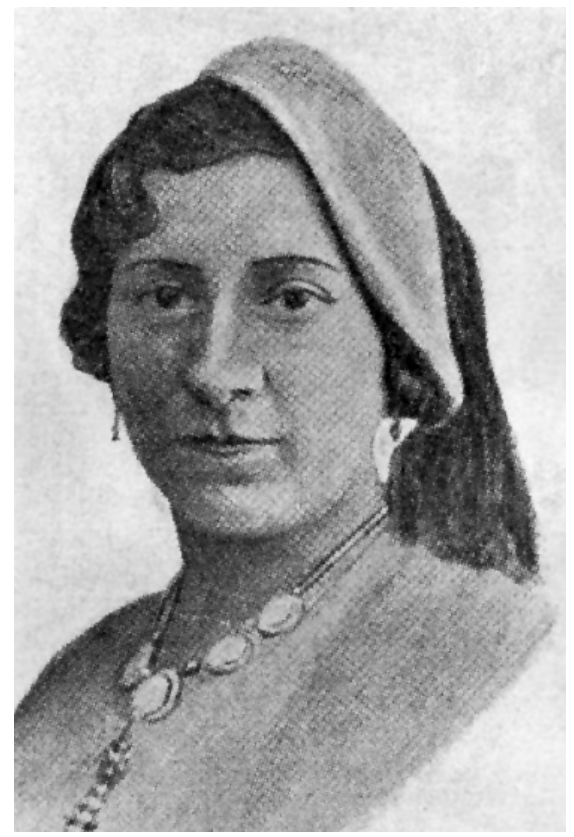

Rosa Urraca Pastor. 